\title{
Cross-national associations between parent and peer communication and
}

psychological complaints

The final publication is available at Springer via http://dx.doi.org/10.1007/s00038-009-5415-7

Carmen Moreno ${ }^{1}$, Inmaculada Sánchez-Queija ${ }^{2}$, Victoria Muñoz-Tinoco ${ }^{1}$, Margarida Gaspar de Matos ${ }^{3}$, Lorenza Dallago ${ }^{4}$, Tom Ter Bogt ${ }^{5}$, Inês Camacho ${ }^{3}$, Francisco Rivera ${ }^{6}$

${ }^{1}$ Department of Developmental and Educational Psychology, University of Seville (Seville, Spain)

${ }^{2}$ Department of Developmental and Educational Psychology, UNED (Madrid, Spain)

${ }^{3}$ Faculty of Human Kinetics, Technical University of Lisbon, (Lisbon, Portugal)

${ }^{4}$ Faculty of Psychology, University of Padua (Padua, Italy)

${ }^{5}$ Faculty of Social Sciences, University of Utrecht (Utrecht, Netherlands)

${ }^{6}$ Department of Psychology, University of Huelva (Huelva, Spain) 


\section{Abstract}

Objectives: To assess whether or not communication with parents and with peers is related to experiencing psychological complaints in an attempt to explore the hypotheses of continuity and compensation or moderation between contexts.

Methods: Questions on communication with their parents and peers, as well as on the frequency with which they experience psychological complaints were answered by 200 857 adolescents from 36 countries.

Results: A cluster analysis detected four groups of adolescents. Those with better communication in both social contexts were the ones showing less psychological complaints. Moreover, we have found (using a regression analysis) that good communication with peers does not improve their experience of psychological complaints if the communication with parents is not good.

Conclusions: We conclude that our findings are consistent with the continuity hypothesis and against the compensating or moderating one.

Keywords: family communication, peers communication, family-peers relationships, adolescent adjustment, cross-cultural research 


\section{Introduction}

At present, neither experts nor non-experts question the relevance of family and peers as socialization contexts. Both, the influence of family relationship dynamics on psychosocial adjustment, as well as that of peer relationship experiences have been quite thoroughly documented. In this way, there is much evidence for the connection between difficulties in emotional bonding with parents during childhood and internalization and externalization problems during adolescence and adulthood ${ }^{1}$. There is fewer evidence on the fact that difficulties in establishing satisfactory relationships with peers and in developing friendship bonds may lead to similar mid- and long-term problems ${ }^{2}$.

At the same time that interest arises to study the influence of these experiences within the family and among peers, a new motivation comes forth to elucidate in what ways these experiences are interrelated. Rubin et al. ${ }^{3}$ point out that there are at least three different ways of understanding the interaction between family and peer contexts, which could be summarized as continuity, independence and moderating effects.

As for the first, the most traditional connection found in the literature is that which places family context as the departing point and privileged environment to acquire those skills needed for peer interactions ${ }^{4}$; skills which will increase in relevance as adolescence is approached $^{5,6}$. From this perspective, family continues to be a fundamental pillar during adolescence since it allows adolescents to face the new developmental tasks of this stage of life ${ }^{7}$. If family relationships work out well, peer relationships would probably be satisfactory as well ${ }^{8,9}$, and both would have a positive, or even an additive, effect on psychological adjustment ${ }^{10,11}$. This way of conceiving the interaction between family and peer experiences is determined by the idea of continuity among contexts.

A second possibility is that both family context and peer context exert independent effects on adolescent adjustment. Both adolescent peer relationships and adolescent family relationships 
have different dynamics as well as specific and characteristic features and tasks. In this way, for example, whereas peer relationships are based on symmetry, asymmetry prevails in relationships with parents. Outstanding differences are also found related to the status of each member in the relationship, activities performed in each context, etc. Seen from this perspective, families and peers would both contribute significantly, but differently, to psychological adjustment ${ }^{12}$. It could even be said that there is an optimum discontinuity level between both contexts; a discontinuity which is necessary in order to help adolescents walk through this stage extracting socializing advantages from each of these two contexts.

The third possibility is that in which good quality peer relationships might buffer the negative impact of bad family relationships during adolescence ${ }^{13}$. The few studies performed with the aim of confirming or falsifying this hypothesis provide some evidence in favour of a buffering interaction. They show, for example, that a more or less wide network of friends decreases the strenth of the association between living in a violent family environment and having behavioural problems or suffering from victimization by peer bullies ${ }^{14}$. Laible et al. ${ }^{15}$ assign even greater importance to peer relationships during adolescence on account of the fact that they find that those adolescents who establish insecure attachments with their parents and secure ones with their peers show a better adjustment than adolescents who establish secure attachments with parents and insecure ones with peers. Rubin et al. ${ }^{3}$ go in depth into the relationship dynamics within the family and among peers, and find that family and peer relationship experiences contribute independently, as well as jointly, to adjustment. They also found sex based differences in this interaction. In this way, for example, a moderately good quality friendship adjusts the negative effects of low maternal support on internalization problems only among girls. These authors think it is also possible to talk about a buffering interaction when the quality 
of family relationships takes the leading role since they observe that among boys, poor quality friendships have less effect on perceived competence when there is a higher perception of maternal support.

Lastly, it is important to point out that these relationship experiences are biased by cultural variables. Certain recent cross-cultural research studies show that family and peer relationships have different effects on adolescents' adjustment depending on the adolescents' culture of origin ${ }^{16,17}$. It is therefore necessary to take into account that cultural meanings connected to social behaviours and relationships (for example, how friendship is conceived, what bearing it is given, to what extent peer relationships are fostered, which behaviours are accepted socially between parents and children, what differences and similarities can be found between both contexts, what level of mutual contact and understanding is common and usual, etc.) can have an effect on the connection between experiences in each context and adjustment, as well as on the interaction between these experiences.

For the purposes of this paper, we have selected communication with parents and with peers as independent variables since they are some of the variables offering more information on the quality of relationships during adolescence ${ }^{18,19}$. In this sense, adolescents spontaneously telling their parents about their activities or concerns is an indicator of relationship adjustment ${ }^{20}$. Likewise, there are many authors who consider self-revelation as a key and characteristic feature of friendship relationships during adolescence, functioning as well as an indicator of intimacy ${ }^{21}$.

As for our selection of the dependent variable, there is much empirical evidence supporting the connection between the socialization experience in different developmental contexts and psychosocial adjustment. Self-esteem and life-satisfaction are variables which have often been used as positive developmental outcomes ${ }^{22}$, and 
depression and behavioural problems ${ }^{19}$ again as negative outcomes. There is also some tradition of linking socialization experience with healthy and unhealthy behaviours ${ }^{23}$. Our aim in this paper was to focus on a series of symptoms or discomforts revealed by adolescents (feeling low, feeling irritable or bad tempered, feeling nervous, having sleeping difficulties) which comprises the subscale of psychological symptoms of the HBSC survey.

\section{Methods}

\section{Participants}

The data presented here come from the World Health Organization collaborative Health Behaviour in School-aged Children (HBSC) study. HBSC is an international collaboration between research teams across Europe and North America which follow the aim of obtaining insight into and a further understanding of adolescent health.

The selected population are young people aged 11, 13 and 15 attending school with the desired mean age for the three age groups being $11.5,13.5$ and 15.5. In each participating country, a minimum of 95 percent of the eligible target population has to be within their sample frame. In the majority of countries, national representative samples were drawn and samples were stratified to ensure representation by, for example, geography, ethnic group and school type. Cluster sampling was used, the primary sampling unit being school class (or school where a sampling frame of classes was not available). The recommended sample size for each of the three age groups was approximately 1500 students, assuming a $95 \%$ confidence interval of $+/-3$ percent around a proportion of 50 per cent and allowing for the clustered nature of the samples. 
We worked with the international sample formed by the 36 countries that took part in the HBSC 2005-06 survey (204 534 adolescents). The sample's distribution was as follows: $33 \%$ were 11 year olds (66 707 adolescents); $34 \%$ were 13 year olds (69 954); and the rest, $33 \%$, were 15 year old adolescents $(67873)$. As for sex distribution, 104301 were girls (51\% of the sample) and 100233 were boys (49\%).

\section{Instruments}

To test the hypothesis, we used the communication variable: "How easy is it for you to talk to the following persons about things that really bother you?" which comprises four response categories: "very easy", "easy", "difficult" and "very difficult". We further differentiated the answers given by adolescents according to the person: "father", "mother", "friends of the same sex" and "friends of the opposite sex". Adolescents who answered "don't have" or "don't see" with regard to the different persons were not included in the sample described above (father (6.9\%), mother (2.4\%), same sex friend (3.4\%) and opposite sex friend $(8.5 \%))$.

For the purposes of our paper we also constructed a "psychological complaints" subscale based on "The HBSC Symptom Check List (HBSC-SCL)"24. This scale has been used in HBSC surveys since 1986 and is considered as a good non-clinical measure of mental health, showing moderate to high correlation with psychological well-being, depressive moods and physical well-being ${ }^{25}$. Several research projects suggest ${ }^{25}$ that the scale reflects two facets -one psychological and one somatic facet. The question included in the questionnaire was: "In the last 6 months: how often have you had the following....?". In accordance with our aim to analyze the mere psychological complaints and in line with the work of Hetland et al. ${ }^{26}$ the mean item scores of the following symptoms are calculated "feeling low", "irritability or bad temper", "feeling nervous", "difficulties in 
sleeping", and "feeling dizzy". Answer categories are "about every day" (1), "more than once a week" (2), "about every week" (3), "about every month" (4) and "rarely or never" (5).

\section{Procedure}

Data were collected through a school-based survey using classroom administered selfcompletion questionnaires in each participating country and region, with requirements in terms of sampling, questionnaire items and survey administration being set out in a standardised research protocol. Participation in the survey was voluntary, with assurance provided in terms of confidentiality and anonymity. Each country respected ethical and legal requirements in their countries for this type of survey. Full details of the study's development and methods employed can be found in this supplement and elsewhere ${ }^{27-30}$.

\section{Results}

We first analyzed the psychological complaints measure and found significant sex-related differences $(t(199894.562)=-53.3254, p<.001)$, showing a greater discomfort rate among girls (mean $(X)=2.31$, standard deviation $(D E)=.87)$ than among boys $(X=2.11$, $D E=.83)$. As for age trends, we found that psychological discomfort increased as age $\operatorname{did}($ Brown-Forsythe $(2,198399.70)=2547.007, p<.001):(X=2.04, D E=.84)$ in the 11 year old groups, $(X=2.22, D E=.85)$ in the 13 year old groups, and $(X=2.37, D E=$ $.85)$ in the 15 year old groups. We also found this trend in the combined sex-age analyses performed $($ Brown-Forsythe $(5,198349.513)=1735.373, p<.001)$, and that sex-based differences were still present in each age interval, and that for both boys and girls, psychological discomfort increases with age.

We then performed a cluster analysis (TwoStep Cluster, Log-likelihood Distance). Respondents were clustered according to their similarity in terms of how easy it was for 
them to communicate with a particular person. The optimal number of clusters was determined with the Bayesian Information Criteria (BIC). The 4 cluster solution displayed the smallest BIC / the smallest decrease in BIC compared regarding a solution with one more cluster. As can be seen in Figure 1, the mean scores (in a 0 to 3 scale) for the whole sample was 1.79 for communicating with fathers, 2.23 with mothers, 2.13 with same-sex friends and 1.63 with opposite-sex friends. Evolving around these mean scores, we have identified four groups which have the following features:

Group 1 ("good communicators"): These $28.9 \%$ of the sample are those adolescents who obtain means above overall mean for communicating with all the people considered.

Group 2 (“good peer communicators”): These adolescents represent $28.3 \%$ of the sample. They have who have a slightly higher difficulty than the overall mean to communicate with fathers and mothers, but at the same time they can communicate with peers (both same-sex and opposite sex) more easily than the total mean.

Group 3 ("no good peer communicators"): They reach very similar scores as the mean of the sample regarding communication with fathers and mothers, but much lower scores regarding communication with peers (with both same-sex and opposite-sex, especially with the latter). They make up $29.4 \%$ of the sample.

Group 4 ("no good communicators"): These adolescents (13.3\% of the total sample), have a higher difficulty in communicating with any of the persons considered than the mean of the sample. They have special noteworthy difficulties in communicating with their fathers and mothers.

Figure 1: Adolescent groups in terms of easiness to communicate with different persons (the arrow depicts the average for the total sample) 


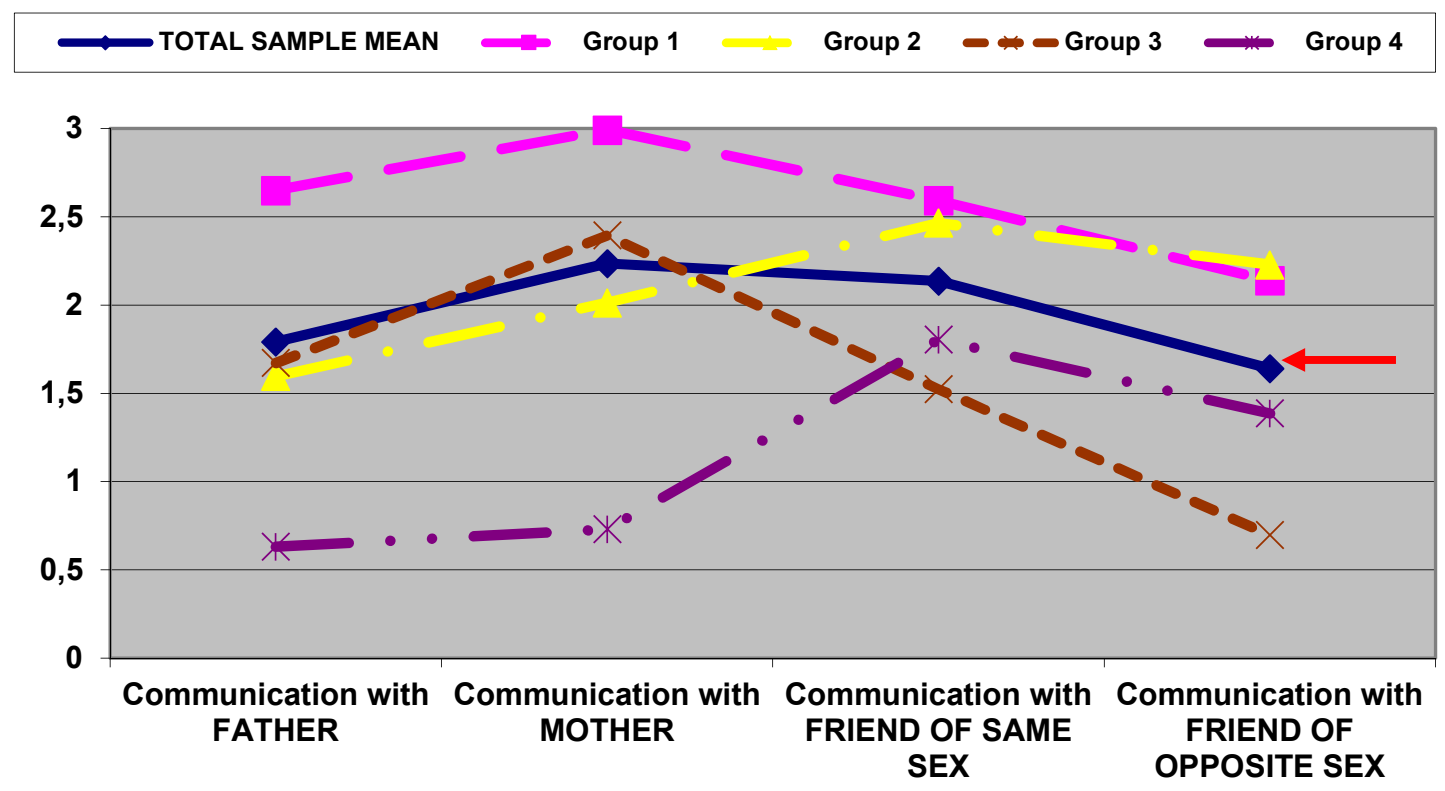

When we analyzed cluster distribution in terms of sex, we found a significant relation $\left(\chi^{2}\right.$ $(3, \mathrm{~N}=147,812)=823.69, p<.001)$ : There are more boys than girls in group $1(32 \%$ boys vs. $26 \%$ girls $)$, whereas the opposite is true in group $3(31.4 \%$ vs. $27.2 \%)$ and in group $4(12.1 \%$ vs. $14.5 \%)$. Group 2 has an equal sex distribution $(28.7 \%$ boys and $28.1 \%$ girls). As for age, we found significant differences $\left(\chi^{2}(6, \mathrm{~N}=147,038)=9576.42, p<\right.$ $.001)$. The percentage of adolescents in groups 1 (37.3\% 11 year olds, $28.6 \% 13$ year olds and $22.3 \% 15$ year olds) and $3(37.7 \% 11$ year olds, $30.6 \% 13$ year olds and 21.4 $\% 15$ year olds) decreased as age increased; whereas the opposite is true for groups 2 (age distribution is: $17.0 \%, 27.6 \%$ and $38.5 \%$, for 11,13 and 15 year olds, respectively) and 4 (age distribution is $8.1 \%, 13.2 \%$ and $17.8 \%$ for 11,13 and 15 year olds, respectively). Upon analyzing groups in terms of sex and age combinations, we also found significant differences $\left(\chi^{2}(15, \mathrm{~N}=147038)=10777.40, p<.001\right)$ in line with those described above for both variables in each of the groups.

Next, we used a one-factor ANOVA analysis to explore possible relations between these different adolescent groups and the experience of psychological complaints. The results are depicted in Table 1. As shown, there are statistically significant differences between 
the four groups $(F(3,051.47)=2461.396, p<.001)$, with an effect size of $\eta^{2}=.05$. Adolescents in Group 1 are the ones with the lowest significant scores, followed by Groups 3 and 2, and lastly by Group 4 which has the highest scores (greater discomfort). After applying Cohen's $d$ test of effect size, we can conclude that there are significant differences with adequate effect size between Group 1 and Groups 2 (Cohen's $d=0.3$ ), 3 (Cohen's $d=0.3$ ) and 4 (Cohen's $d=0.7$ ), and between Group 4 and Groups 2 (Cohen's $d=0.4)$ and 3 (Cohen's $d=0.5$ ).

Table 1. Results from the ANOVA analysis between adolescent groups in terms of their easiness to communicate with different persons and how they experience psychological discomfort

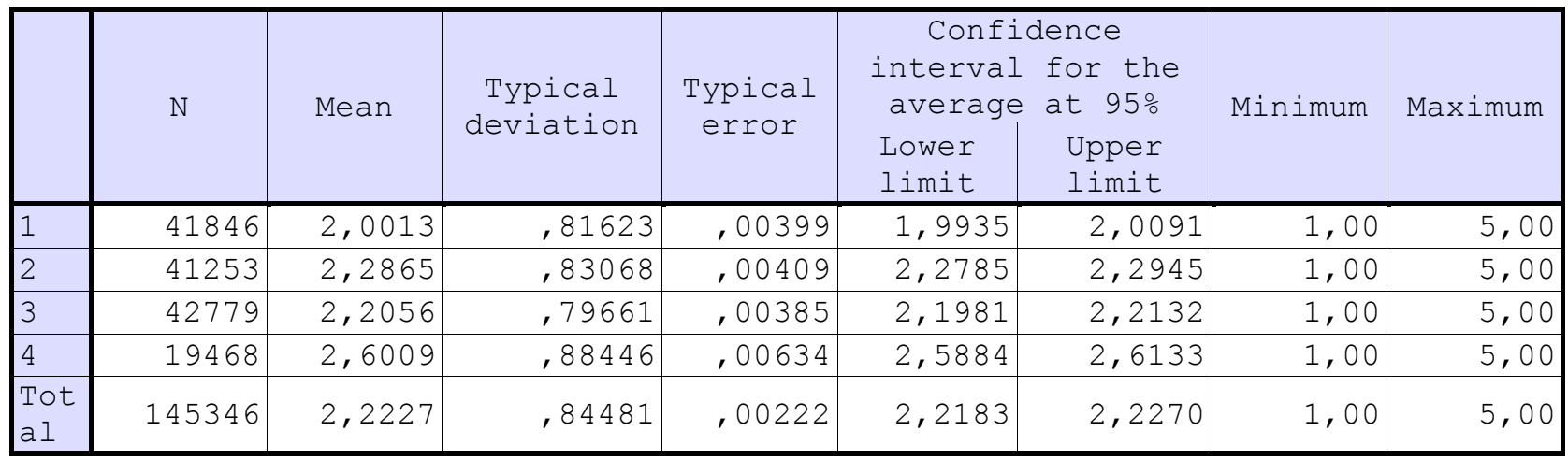

In order to verify results obtained using the cluster analysis and the ANOVA derived from it, we then performed a regression analysis which would give us the relevance of each of these communication variables on psychological complaints.

Our first step was to perform a regression analysis to examine which proportion of variance in the psychological discomfort index can be predicted by family communication and peers communication variables. Furthermore it was tested if a statistically significant interaction (moderation effect) between both variables could be detected. After analyzing the regression equation of each possible combination of the covariates, we reached a model $(F(1,7164.345)=10820.971, p<.001)$ in which family 
communication $\left(R^{2}\right.$ corrected $\left.=0.07\right)$ is the only variable with enough weight to be introduced in the equation, whereas the introduction of the peer communication variable (change in $R^{2}=0.001$ ) and of the interaction between both variables (change in $R^{2}=$ 0.000) yielded no substantial differences in the predicted variance of the outcome.

In order to verify if sex bears an influence on this relation, we explored independent models for boys and girls, reaching the conclusion that sex does not determine any changes in the model's structure, since in both cases, the family communication variable was found to be the only relevant variable $(F(1,2014.475)=3166.971, p<.001$ for the boys' model; $F(1,4679.196)=6956.045, p<.001$ for the girls' model $)$. However, this variable is given a different weight in the boys' group since family communication represents an explained variable $\left(R^{2}=0.043\right)$ inferior to that of the girls' group $\left(R^{2}=\right.$ 0.084). In any case, the change in the explained variance after the introduction of peer communication variable $\left(R^{2}<0.002\right)$ and the interaction variable $\left(R^{2}=0.00\right)$ in both models proved to be irrelevant.

Once we found out that the interaction between family communication and peer communication variables was irrelevant, we took a second approach by means of a new regression model analysis in which age and sex were included as Independent variable. In the first analysis we obtained an $R^{2}=.04$. In the second analysis we added family communication variables (father and mother), obtaining an $R^{2}=.08$. In the third analysis, we added communication with peers (same-sex and opposite-sex friends), which in spite of entering the equation with a significance of $p<.001$ did not add explanatory power, resulting in an $R^{2}=.082$.

Table 2. B Psychological complaints coefficients by countries

\begin{tabular}{|c|c|c|c|c|c|c|c|}
\hline Country & Gender & Age & Father & Mother & $\begin{array}{c}\text { Friend } \\
\text { Same Sex }\end{array}$ & $\begin{array}{c}\text { Friend } \\
\text { Oppos Sex }\end{array}$ & $\begin{array}{c}\mathbf{R}^{2} \\
\text { cor }\end{array}$ \\
\hline
\end{tabular}




\begin{tabular}{|c|c|c|c|c|c|c|c|}
\hline Austria & $-.11^{* *}$ & $.05 * *$ & $-.10 * *$ & $-.10 * *$ & $-.03^{*}$ & $.05^{* *}$ & .08 \\
\hline Belgium & $-.14 * *$ & $.05 * *$ & $-.10 * *$ & $-.09 * *$ & -.01 & $.03^{*}$ & .07 \\
\hline Bulgaria & $-.14 * *$ & $.07 * *$ & $-.11 * *$ & $-.12 * *$ & -.02 & $.05 *$ & .10 \\
\hline Canada & $-.15 * *$ & $.06 * *$ & $-.12 * *$ & $-.10 * *$ & $-.04 *$ & $.04^{*}$ & .10 \\
\hline Croatia & $-.16 * *$ & $.07 * *$ & $-.09 * *$ & $-.10 * *$ & $-.03 *$ & $.03^{*}$ & .09 \\
\hline Czech Republic & $-.26 * *$ & $.05 * *$ & $-.08 * *$ & $-.07 * *$ & .02 & .02 & .08 \\
\hline Denmark & $-.11^{* *}$ & $.04^{* *}$ & $-.11^{* *}$ & $-.07 * *$ & $-.03^{*}$ & $.04 * *$ & .08 \\
\hline Estonia & $-.14 * *$ & $.08 * *$ & $-.08 * *$ & $-.15 * *$ & $-.05 *$ & -.01 & .09 \\
\hline Finland & $-.15^{* *}$ & $.05^{* *}$ & $-.13 * *$ & $-.13 * *$ & $-.05 * *$ & $.08 * *$ & .12 \\
\hline France & $-.25 * *$ & $.04 * *$ & $-.11^{* *}$ & $-.10 * *$ & .005 & $.04 * *$ & .10 \\
\hline Germany & $-.17 * *$ & $.04 * *$ & $-.09 * *$ & $-.08 * *$ & -.02 & $.03 *$ & .07 \\
\hline Hungary & $-.15^{* *}$ & $.07^{* *}$ & $-.06 * *$ & $-.12 * *$ & -.04 & $.05^{* *}$ & .06 \\
\hline Iceland & $-.10 * *$ & $.09 * *$ & $-.16 * *$ & $-.13 * *$ & $-.03 *$ & $.03 * *$ & .14 \\
\hline Ireland & $-.10 * *$ & $.08 * *$ & $-.12 * *$ & $-.10 * *$ & $-.08 * *$ & $.04^{* *}$ & .12 \\
\hline Israel & $-.10 * *$ & $.04 * *$ & $-.07 * *$ & $-.12 * *$ & $-.05^{*}$ & $.05^{*}$ & .03 \\
\hline Italy & $-.17 * *$ & $.05 * *$ & $-.13 * *$ & $-.06 * *$ & $-.03^{*}$ & $.04 *$ & .09 \\
\hline Latvia & $-.21 * *$ & $.06 * *$ & $-.04 * *$ & $-.09 * *$ & -.01 & .01 & .06 \\
\hline Lithuania & $-.24 * *$ & $.10^{* *}$ & $-.09 * *$ & $-.07 * *$ & -.01 & -.02 & .10 \\
\hline Luxembourg & $-.27^{* *}$ & $.08^{* *}$ & $-.10 * *$ & $-.11^{* *}$ & -.02 & $.03 *$ & .13 \\
\hline Malta & -.10 & $.07^{* *}$ & $-.07 *$ & -.04 & .01 & $.08^{* *}$ & .05 \\
\hline Netherlands & $-.21 * *$ & $.05^{* *}$ & $-.10 * *$ & $-.08 * *$ & -.02 & .01 & .08 \\
\hline Norway & $-.12 * *$ & $.03^{* *}$ & $-.11^{* *}$ & $-.11 * *$ & $-.04^{*}$ & .01 & .09 \\
\hline Poland & $-.16 * *$ & $.04 * *$ & $-.09 * *$ & $-.11 * *$ & $-.07 * *$ & .01 & .08 \\
\hline Portugal & $-.23 * *$ & $.05^{* *}$ & $-.08 * *$ & $-.08 * *$ & $-.04 *$ & $.05^{* *}$ & .08 \\
\hline Romania & $-.23 * *$ & $.11^{* *}$ & $-.10 * *$ & $-.06 * *$ & .02 & $.03 *$ & .10 \\
\hline Russian Feder. & $-.22 * *$ & $.03 * *$ & $-.04 * *$ & $-.09 * *$ & $-.03^{*}$ & .02 & .04 \\
\hline Slovakia & $-.09 * *$ & $.05 * *$ & $-.12 * *$ & $.05^{*}$ & .03 & -.02 & .05 \\
\hline Slovenia & $-.10 * *$ & $.08^{* *}$ & $-.09 * *$ & $-.09 * *$ & .01 & $-.03 *$ & .07 \\
\hline Spain & $-.23 * *$ & $.05^{* *}$ & $-.14^{* *}$ & $-.09 * *$ & -.01 & $.03 *$ & .10 \\
\hline Sweden & $-.20 * *$ & $.07^{* *}$ & $-.14 * *$ & $-.09 * *$ & $-.04 *$ & $.05^{* *}$ & .14 \\
\hline Switzerland & $-.18 * *$ & $.03 * *$ & $-.12 * *$ & $-.07 * *$ & $-.03 *$ & $.04 *$ & .08 \\
\hline Turkey & $-.18 * *$ & $.03 *$ & $-.10 * *$ & $-.06 * *$ & $-.03 *$ & $.04 * *$ & .05 \\
\hline Ukraine & $-.26 * *$ & $.04^{* *}$ & $-.06 * *$ & $-.08 * *$ & $-.03 *$ & .01 & .06 \\
\hline Macedonia & $-.12 * *$ & $.09 * *$ & $-.10 * *$ & $-.03 *$ & .02 & .02 & .07 \\
\hline Un. Kingdom & $-.13 * *$ & $.02 * *$ & $-.10 * *$ & $-.13^{* *}$ & $-.06 * *$ & $.05^{* *}$ & .09 \\
\hline USA & $-.24 * *$ & $.07^{* *}$ & $-.08 * *$ & $-.13 * *$ & $-.05^{*}$ & $.03 *$ & .10 \\
\hline
\end{tabular}

$* * \mathrm{P}<0.01 ; * \mathrm{P}<0.05$ (Father $=$ Communicacion with father: Mother $=$ communication with mother; Friend Same Sex: communicacion with Same Sex Friend; Friend OpposS: communication with Opposite Sex Friend)

The last analysis performed was the application of the previous regression model for each of the countries taking part in the study. Table 2 shows results obtained. As can be seen, sex is the variable explaining the most variance (girls report more psychological complaints than boys for all countries), followed by communication with parents, age (older adolescents report more psychological complaints than younger adolescents, for all countries analyzed) and communication with peers. Communication with fathers is also related to psychological complaints in all countries. In the case of mothers, communication is related to psychological complaints in all countries, except Malta. As for peers, the easier the communication with same sex friend is, the fewer psychological 
complaints appear. Nevertheless, the easier the communication with the opposite sex, the higher the number of psychological complaints. However, it must be noted that these last relationships do not hold true for all of the countries.

\section{Discussion}

The results found that in spite of the similarities in behave and experiences of adolescents, they have too important differences between the adolescents which lead us to coin the term "kind of adolescences". Regarding health and social relationship quality issues, sex and age mark important differences between adolescents.

With regards to sex differences, our results suggest that boys and girls experience adolescence differently and have different assets and needs. This is at least the case when regarding psychological complaints and the quality of their communication with their family or with their peers. In general, we can say that even if differences are not very pronounced in some cases, they are consistent in showing that girls tend to express more psychological complaints and that their communication needs - whether with their families or peers - are not met.

With higher age, there is a clear tendency for adolescents to experience greater psychological discomfort, more communication problems with their families, and a slight improvement in their easiness to communicate with peers which is probably in part due to better cognitive abilities as well as their greater capacity of analysis and self-reflection, A further discussion of sex and age issues can be found in the HBSC 2005/06 Report ${ }^{29}$. The primary focus of our work was to assess whether or not communicating with family members and with peers was related to experiencing psychological complaints, and to analyse how these contexts function; in terms of continuity vs. compensation (or moderation). 
Our results show that at least for the experience of psychological discomfort, and with the measures used in this research, the relationship with one's parents has a specially powerful meaning for adolescents as compared to their relationship with peers (whether of the same or opposite sex). Related to self-esteem, a similar result is found by Wilkinson $^{31}$.

Linked to the idea of discontinuity mentioned in the introduction, the concept of independence between contexts. In this way, family and peers can influence adjustment in a relevant way, but each in terms of different contents of development. In this way, both the ANOVA analysis between the different adolescent groups obtained through the conglomerate analysis, as well as the regression analysis, show stronger association between family communication and the absence of psychological complaints, whereas peer communication seems to play a smaller role in explaining the presence or absence of this type of symptomatology. However, communication might not be the variable most suitable when it comes to reflect the impact that peers have on health, at least during middle adolescence. During this time, peers seem to play a central role. Research, nevertheless, confirms that key experiences are those evolving around having fun, spending time together, doing things together and physical contact. Talking with each other, however, appears more as a way to keep contact than as a method of exchanging intimate information. In fact, many adolescents say that talking about personal episodes and amusing stories is one of the most relevant activities ${ }^{32}$. This tendency changes during late adolescence, where intimacy acquires greater relevance, and probably with it does also the effect of peer relationships on health issues.

On the other hand, our results show that at this age, there are differences behind samesex or opposite-sex peer relationships. Even if our data do not give us sufficient information that is neededto assert it we think that easiness to communicate with opposite- 
sex peers might be related to having a partner. Given that the motivation behind seeking a partner at this age is related to emotional support ${ }^{33}$, one might imagine that those adolescents receiving less support from their families would be the ones to get more involved in premature couple relationships.

As mentioned at the beginning of this discussion section, some variables (such as sex and age) mark important developmental differences between adolescents. However, there are also important similarities in the processes characterizing this developmental stage as such. Cross-national similarities regarding the importance of the family as compared to peers is a good example of this, given that countries differed only slightly from one another.

As future lines of research go in depth into the differential influence of family and peer experiences, it would be relevant to improve the quality of measures and to include other psychological adjustment variables in the research design, such as that of positive health (e.g. life satisfaction, self esteem) or other psychosocial adjustment contents, such as that of loneliness, for all of which we would probably find a greater effect of peer communication. Similarly, it would be important to diversify the content of communication adding specific communication domains and situations as a way to verify which forms of communication are more relevant in each context. Another strategy which would help modulate results obtained would be to include explanatory relationship experiences linked to other dynamics different from that of communication, as are those of joint activities, their quality and satisfaction perceived. 


\section{References}

1. Buist KL, Dekovic M, Meeus W, van Aken M. The reciprocal relationship between early adolescent attachment and internalizing and externalizing problem behaviour. J Adolescence 2004;27:251-66.

2. Rubin KH, Bukowski W, Parker J. Peer interactions, relationships, and groups. In Eisenberg N, Ed. Handbook of Child Psychology: Social, emotional, and personality development. $6^{\text {th }}$ ed. New York, USA: Wiley, 2006:571-645.

3. Rubin KH, Dwyer KM, Kim AH, Burgess KB. Attachment, Friendship, and Psychosocial Functioning in Early Adolescence. J Early Adolesc 2004;24:326-56.

4. Hartup WW. Relationships and their significance in cognitive development. In: Hinde RA, Perret-Clemont A, Stevenson-Hinde J, eds. Social relationships and cognitive development. Oxford, UK: Clarendon Press, 1985:66-81.

5. Berndt TJ. Transitions in Friendship and Friends' Influence. In: Graber JA, BrookGunn J, Petersen AC, eds. Transition through adolescence: Interpersonal Domains and Context.: L Erlbaum, 1996:57-84.

6. Brown BB. Adolescents' Relationships with Peers. In: Lerner RM, Steinberg L, eds. Handbook of adolescent psychology. New Jersey, USA: Wiley, 2004:363-94.

7. Noller P. Relationships with parents in adolescence: Process and outcomes. In: Montemayor R, Adams GR, Gullotta TP, eds. Personal relationships during adolescence. Thousand Oak, CA, USA: Sage, 1994:37-77.

8. Mounts NS, Steinberg L. An ecological analysis of peer influence on adolescent grade point average and drug use. Dev Psychol 1995;31:915-22.

9. Sánchez-Queija I, Oliva A. Vínculos de apego con los padres y relaciones con los iguales durante la adolescencia. Rev Psicol Soc 2003;18:71-86. 
10. Helsen M, Vollebergh W, Meeus W. Social support from parents and friends and emotional problems in adolescence. J Youth Adolescence 2000;29:319-36.

11. Cristini F, Santinello M, Dallago L. L'influenza del sostegno sociale dei genitori e degli amici sul benessere in adolescenza. Psicologia Clinica dello Sviluppo 2007;3:503-23.

12. Meeus W, Oosterwegel A, Vollebergh W. Parental and peer attachment and identity development in adolescence. J Adolescence 2002;25:93-106.

13. Gauze C, Bukowsky WM, Aquan-Assee J, Sippola LK. Interactions between Family Environment and Friendship and Associations with Self-Perceived WellBeing during Early Adolescence. Child Dev 1996;67:2201-16.

14. Criss MM, Pettit GS, Bates JE, Dodge KA, Lapp AL. Family adversity, positive peer relationships, and children externalizing behavior: A longitudinal perspective on risk and resilience. Child Dev 2002;74:1220-37.

15. Laible DJ, Carlo G, Raffaelli M. The differencial relations of parents and peer attachment to adolescent adjustment. J Youth Adolescence 2000;29:45-59.

16. Ciairano S, Bo G, Jackson S, Van Mameren A. The mediator role of friends in psychological well-being and the use of psychoactive substances during adolescence: a comparative research in two European countries. 8th EARA 2002, Oxford, UK.

16.17. Brown RB, Mounts N.S. Linking parents and family to adolescent peer relations: ethnic and cultural considerations. San Francisco: Jossey-Bass. 2007.

17.18. Noller P, Callan VJ. The adolescent in the family. London: Routledge, 1991.

18.19. Yu SL, Clemens R, Yang HM, et al. Youth and parental perceptions of parental monitoring and parent-adolescent communication, youth depression, and youth risk behaviours. Soc Behav Personal 2006;34:1297-310. 
19.20. Stattin H, Kerr M. Parental monitoring: a reinterpretation. Child Dev 2000;71:1072-85.

20.21. Berndt TJ, Keefe K. Friends' Influence on Adolescents' Adjustment to School. Child Dev 1995;66:1312-29.

21.22. Ma CQ, Huebner ES. Attachment relationships and adolescents' life satisfaction: Some relationhips matter more to girls than boys. Psychol Schools 2008;45:17790.

22.23. Brown BB, Dolcini MM, Leventhal A. Transformation in Peer Relationships at Adolescence: Implications for Health-Related Behavior. In: Shulenberg J, Maggs J, Hurrelmann K, eds. Health risk and Developmental Transitions During Adolescence. New York, USA: Cambridge University Press, 1997:161-89.

23.24. Haugland S, Wold B, Stevenson J, Aaroe LE, Woynarowska B. Subjective health complaints in adolescence. A cros-national comparison of prevalence and dimensionality. Eur J Public Health 2001;11:4-10.

24.25. Ravens-Sieberer U, Erhart M, Torsheim T, et al. and the HBSC Positive Health Group. Health complaints in adolescence. Eur J Public Health 2008;18(3):294-9.

25.26. Hetland J, Torsheim T, Aaro LE. Subjective health complaints in adolescence: Dimensional structure and variation across gender and age. Scand J Public Health 2002;30(3):223-30.

26.27. Roberts C, Freeman J, Samdal O, et al. \& MDG and the HBSC study group. The Health Behaviour in School-aged Children (HBSC) study: methodological developments and current tensions. Int J Public Health 2009; (OVERVIEW PAPER 5). 
27.28. Roberts C, Currie, C, Samdal O, Currie, D, Smith, R, Maes, L. Measuring the health behaviours of adolescents through cross-national survey research: recent developments in the Health Behaviour in School-aged Children (HBSC) study. J Public Health 2007;15:179-86.

28.29. Currie C, Nic Gabhainn S, Godeau E, et al., eds. Inequalities in young people's health: HBSC international report from the 2005/2006 Survey. Health Policy for Children and Adolescents, No. 5. Copenhagen, WHO Regional Office for Europe, 2008.

29.30. Currie C, Gabhainn SN, Godeau E. The Health Behaviour in School-Aged Children: WHO Collaborative Cross-National (HBSC) Study: origins, concept, history and development 1982-2008. Int J Public Health 2009; (OVERVIEW

\section{PAPER 4).}

30.31. Wilkinson RB. The Role of Parental and Peer Attachment in the Psychological Health and Self-Esteem of Adolescents. J Youth Adolescence 2004;33:479-93.

31.32. Cotterell J. Social Networks in Youth and Adolescence. London: Routledge, 2007.

32.33. Zani B, Cicognani E. Sexuality and intimate relationships in adolescence. In: Jackson S, Goossens L, eds. Handbook of Adolescent Development. East Sussex, UK: Psychology Press, 2006: 200-222. 


\section{Conflict of Interest}

The authors declare no conflict of interest.

\section{Address for Correspondence}

Carmen Moreno

Dpto. de Psicología Evolutiva y de la Educación. Facultad de Psicología. Universidad de Sevilla.

C/ Camilo José Cela, s/n. 41018

Sevilla (Spain)

mcmoreno@us.es

phone: +34954557678 